\title{
A Regional Landslide Stability Analysis Method under the Combined Impact of Rainfall and Vegetation Roots in South China
}

\author{
Qinghua Gong $\mathbb{D},,^{1,2,3}$ Jun Wang $\mathbb{D}^{1,2,3}$ Ping Zhou $\mathbb{D}^{1,2}$ and Min Guo ${ }^{4}$ \\ ${ }^{1}$ Guangdong Open Laboratory of Geospatial Information Technology and Application, Guangzhou 510070, China \\ ${ }^{2}$ Guangzhou Institute of Geography, Guangdong Academy of Science, Guangzhou 510070, China \\ ${ }^{3}$ Southern Marine Science and Engineering Guangdong Laboratory (Guangzhou), Guangzhou 511458, China \\ ${ }^{4}$ Guangdong Geologic Survey Institute, Guangzhou 510071, China \\ Correspondence should be addressed to Jun Wang; wangjun@gdas.ac.cn
}

Received 20 January 2021; Revised 2 June 2021; Accepted 8 July 2021; Published 20 July 2021

Academic Editor: Youjun Ning

Copyright (c) 2021 Qinghua Gong et al. This is an open access article distributed under the Creative Commons Attribution License, which permits unrestricted use, distribution, and reproduction in any medium, provided the original work is properly cited.

\begin{abstract}
The aim of this study was to develop a regional landslide stability analysis method considering the combined impact of rainfall and the roots of vegetation in densely vegetated areas. A typical mountainous watershed in the Nanling National Nature Reserve of South China was chosen as the study area. First, the unmanned aerial vehicle (UAV) method was used to obtain surface element information including topography, vegetation, and landslides. Five main plant species were identified. The RipRoot model was then used to calculate the additional cohesion of these five plant species, and the relationship between the root systems of the different plant species and the soil shear strength was subsequently revealed. Finally, the root cohesion was introduced into the stability index mapping model (SINMAP), and the receiver operating characteristic curve (ROC) method was used to calculate the accuracy of slope stability when considering only soil cohesion as well as the composite cohesion of both soil and roots. The results showed significant differences in the root cohesion of different plants in the study area and a significant increase in the calculation accuracy (from 90\% to 95.6\%) when root cohesion was considered in the landslide stability calculation. These study results not only enrich theoretical studies on the impact of vegetation roots on landslide stability but also provide a scientific support for preventing disasters in mountainous landslide-prone areas.
\end{abstract}

\section{Introduction}

Landslides occur due to the deformation of rock and soil on slopes under the influence of rainfall, human activities, slope topography, geology, vegetation, and other factors [1]. Rainfall (especially heavy rainfall) is the main cause of landslide disasters generally causing a regional mass effect that can result in catastrophic consequences within a short time frame, such as huge economic losses, heavy casualties, and significant damage to the ecological environment [2-4]. According to a survey of 290 counties and cities in China, $90 \%$ of the total number of landslides were induced by heavy rainfall [5]. Such landslides are thus representative of serious geological disasters that occur in China and globally.

It is widely known that the main aim of landslide mitigation is to determine the probability and location of the potential occurrence of shallow landslides. Landslide stability analyses are conducted in this respect, and statistical analyses and physical model methods are the main method employed for rainfall-induced landslides. Statistical methods are based on the use of long-term rainfall and disaster monitoring data [6-10]. However, shallow landslides usually occur as short sudden outbreaks with few signs of early deformation, and historical records and data on the landslide occurrence time and corresponding cumulative rainfall are often lacking. Therefore, it is difficult to utilize statistical samples to form a statistically significant data system that can be employed to conduct stability analyses, and the lack of such data may result in large errors. Quantitative research can be conducted using physical methods based on a hydromechanical model, and the migration of precipitation on the surface and its infiltration into the ground can be clearly 
described. Such methods can be used to analyze and observe changes in pore water pressure of soils that occurs due to precipitation. In addition, specific changes in slope and the corresponding safety factor value can be calculated using the slope stability model. The main physical models used to evaluate landslides associated with rainfall are Shallow Slope Stability model (SHALSTAB) $[11,12]$, the Stability Index MAPping model (SINMAP) [13, 14], and the Transient Rainfall Infiltration and Grid-based Regional Slope Stability model (TRIGRS) [15-19]. The most recognized and widely used models are currently the SINMAP [13, 20-25]. The theoretical basis of using the SINMAP model arises from the fact that it is a large-scale slope stability model utilizing the terrain moisture index obtained from the steady-state hydrological model based on grid units that can be quickly and conveniently calculated.

During landslide formation, each slope occurs in relation to the incline at which it is located, and each slope unit has a relatively clear topographical boundary. Landslides are controlled by the geological elements associated with the slope unit. Therefore, slope is the most ideal unit for studying landslides. However, the SINMAP is still grid unit model and is not extended to slope unit. This study innovatively extended the SINMAP model to slope unit to calculate the stability coefficient of each slope under different rainfall conditions.

Vegetation plays an important role in slope stability, and roots have a mechanical effect in increasing slope stability. To date, studies on the effects of the root fixing of soil have focused mainly on single tensile properties of different plant types $[26,27]$. In addition, studies have focused on the shearresistance characteristics of root-soil composites [28, 29], mechanical reinforcement effect of the root fixing of soil $[30,31]$, and mechanism of root slope protection using a soil model [32-34]. However, most previous research on root systems has been conducted on small or single-plant scales, whereas for regional slopes with a high vegetation coverage, few studies have investigated the roots of vegetation and their effects on slope stability. Furthermore, most research has focused mainly on conducting laboratory tests on the tensile strength of the root systems of different tree species, and related studies evaluating the application of vegetation roots to slope stability zoning on a slope scale are relatively rare.

Therefore, this study innovatively develops a regional landslide stability assessment method that considers the combined impact of different rainfall types and the roots of vegetation on landslide stability in densely vegetated areas. The specific objectives were to provide a scientific and reliable theoretical basis for the mitigation of landslide disasters by (i) proposing a method based on the use of UAV remote sensing data of the surface elements of small watersheds (such as the terrain, vegetation, and landslides); (ii) proposing an improvement of the physical SINMAP model by introducing root cohesion into the landslide stability analysis model (SINMAP) and employing the slope unit as the basic unit; and (iii) producing a landslide susceptibility zoning map associated with different rainfall intensities. To achieve these objectives, a watershed in the core area of the
Nanling National Nature Reserve in South China was selected as the study area. The area has a subtropical monsoon climate with abundant rainfall and a high vegetation coverage. The surfaces of slopes are mostly covered by residual strong weathered rocks with loose structures and fissures, which renders the area extremely prone to landslide disasters.

\section{Materials and Methodology}

2.1. Characterization of Study Area. The Nanling Mountains within the Nanling National Nature Reserve of South China are the largest mountain range in southern China; they act as an important natural geographical boundary between tropical and subtropical regions and they separate four provinces (study location is shown in Figure 1). The mountains also form a watershed dividing between the Pearl River and the Yangtze River, and they play an important ecological role in South China. The study area has a typical subtropical climate with average total annual rainfall of $1705 \mathrm{~mm}$ (multiyear average precipitation ranges from 1452.1 to $2154.5 \mathrm{~mm}$ ) (Figure 2).

The horizontal zonal soil in the study area is red soil. Owing to the large difference in the relative elevation of the mountains and the vertical distribution of moisture and temperature conditions, the distribution of soil types differs considerably with altitude. Yellow soil is distributed below $1500 \mathrm{~m}$, latent yellow soil is distributed within 1500-1800 m, and meadow soil exists at elevations higher than $1800 \mathrm{~m}$. Because of their unique climatic conditions, the Nanling Mountains are an oasis that contain the largest remaining area of unspoiled land at the same latitude in the world.

The various types of forest vegetation within the mountain range include subtropical evergreen broad-leaved forests, coniferous and broad-leaved mixed forests, coniferous forests, and hilltop lowland forests. In the study area, Yushania basihirsuta is mainly distributed on peaks and ridges above $1500 \mathrm{~m}$ where the soil is comprised of granite or sandy shale weathered meadow soil and is thin and rocky with a soft, thick, humus and moss layer on the surface. Trees are extremely low in height and most are small trees or shrubs. Coniferous and broad-leaved mixed forests include the species Cunninghamia lanceolata, Pinus kwangtungensis, and Fagus longipetiolata and are distributed mainly on ridges and on steep slopes at 1000-1500 m. Constructive species include Pinus massoniana and Cunninghamia lanceolata. The soil at this altitude is mountainous yellow soil covered by a thick humus layer. Plant roots are concentrated mainly on the $0-40 \mathrm{~cm}$ surface.

The mountainous part of the study area has steep unstable slopes, strongly cut river valleys, thick weathered soil, strong erosion, and complex climatic conditions. It is prone to mountain disasters, such as collapses, landslides, and mudslides. The area percentage of different slope class is shown in Figure 3. Mountain disasters, such as collapses and landslides, occur mainly in areas where the slopes are steep, where differences in terrain exist, and where the slope of the terrain ranges from $30^{\circ}$ to $40^{\circ}$, and particularly in regions where extensive weathering and rock fragmentation has 


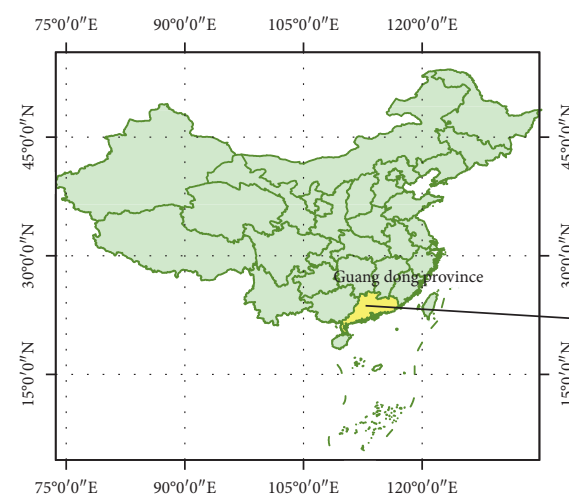

(a)

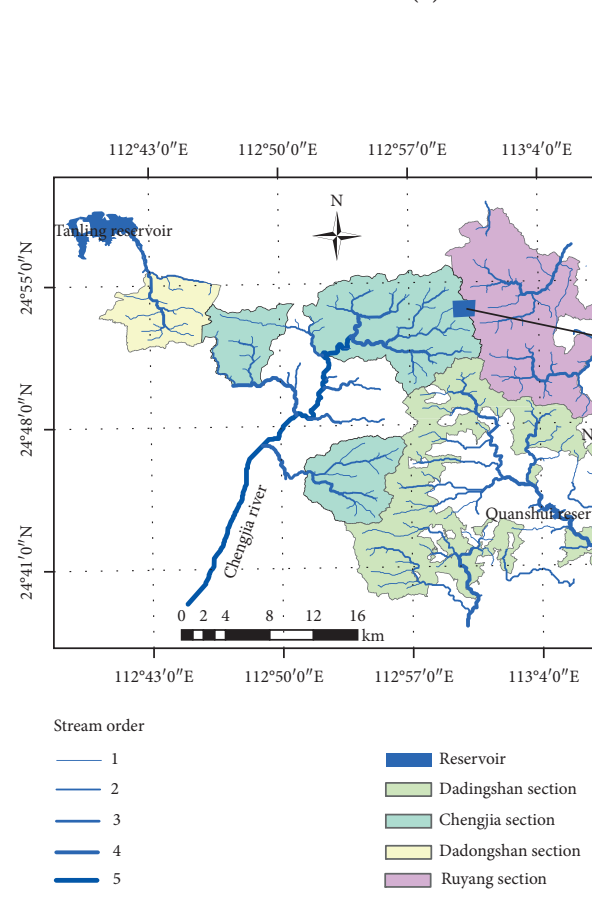

(c)

Figure 1: Location of the study area: (a) map showing the location of Guangdong Province in China, (b) map showing the location of the study area in Guangdong Province, (c) map showing the location of study area in the Nanling National Nature Reserve, and (d) map of the study area and the landslide distribution.

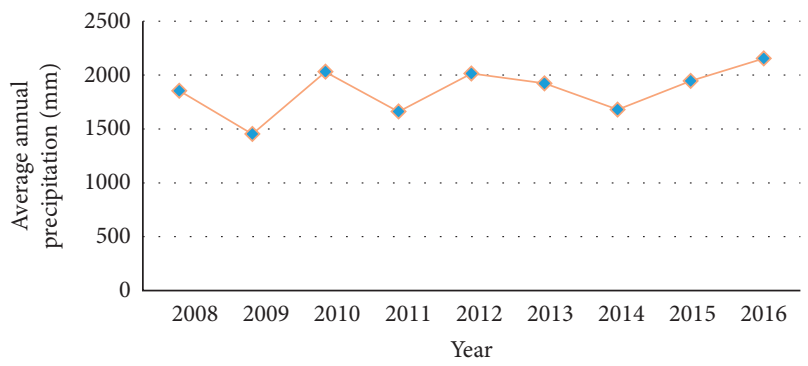

FIgURE 2: The total annual average rainfall from 2008 to 2016.

occurred. Such regions include slopes, the steep portions of river valleys, and slopes along reservoirs and other constructed infrastructure. However, the scale of collapses and landslides is predominantly small, and mass movements tend to be shallow.
2.2. The Flowchart of the Method. The flowchart of this method is shown in Figure 4. The process can be divided into five parts: the topography and vegetation extraction, the vegetation root investigation, the slope unit division based on GIS, the root cohesion calculation, and the slope stability analysis with SINMAP model under the combined impact of rainfall and vegetation roots.

2.2.1. The Topography and Vegetation Extraction. This study used high-resolution UAV remote sensing images obtained in August 2017 as the data source to define the topography and vegetation. In this respect, the UAV was used to acquire stereo image pairs with a high overlap in the study area. Three-dimensional (3D) relative point cloud data were then used to extract $3 \mathrm{D}$ point cloud, which were subsequently used to generate a digital elevation model (DEM) with a 




FIgURE 3: The area percentage of different slope classes in the study area.

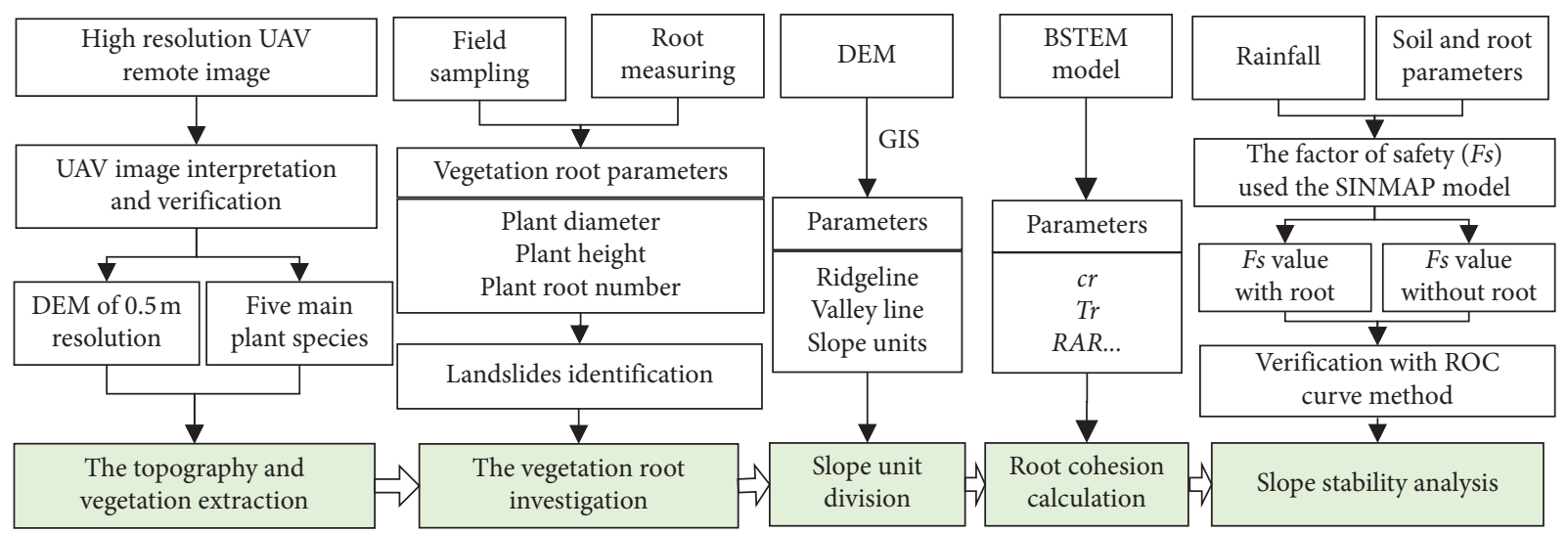

FIGURE 4: The flowchart of the method used in this study.

spatial resolution of $0.5 \mathrm{~m}$. The species of flora were then visually interpreted according to the results of vegetation classification research obtained in the study area [35], which were subsequently verified by intensive field investigations. The main plant species in the study area were finally determined as Yushania basihirsuta, Cunninghamia lanceolata, Pinus massoniana, Pinus kwangtungensis, and Fagus longipetiolata.

2.2.2. The Vegetation Root Investigation. Vegetation root data were obtained via field sampling, and sampling sites were established at different elevations. Plant diameter and height and the numbers of roots with different root diameters were measured. Landslide identification was also conducted using positive UAV remote sensing images. The precipitation data employed were rainfall monitoring data spanning 1950 to 2016 obtained from two rainfall monitoring stations in the study area. The maximum daily rainfall at the peak station was $105.3 \mathrm{~mm}$ and that at the foot of the mountain was $207.6 \mathrm{~mm}$.
2.2.3. The Slope Unit Division Based on GIS. The slope unit is often used to analyze slope stability with respect to landslides. We extended the cells in the original SINMAP model into slope cells, and the stability of each slope under the vegetation coverage and rainfall exposure was then calculated. The method used to divide slope units was based on a DEM generated from the UAV remote sensing results. In this respect, based on the source cutting method and ridgelines and valley lines, slope units were divided using the GIS platform.

2.2.4. The Root Cohesion Calculation. Soil reinforcement research is based on the mechanical properties of plant roots and root-permeated soil is a composite material that has enhanced strength [36]. Vertical deep roots are anchored to stable rock layers through a shallow weathering layer, and shallow roots convert the soil on a slope into a root-soil composite material that improves soil strength. This composite material improves the cohesion of slope soil and increases the safety and stability of the slope. The slip surface 
of shallow landslides in forested areas mostly occurs between the layer with the largest root density and the lower soil body, and such a phenomenon proves that root systems have a controlling effect on shallow landslides.

$\mathrm{Wu}$ [37] and Waldron [38] made an important contribution to the theory of soil reinforcement and determined that soil strength $\left(c_{r}\right)$ is a function of

$$
\begin{aligned}
c_{r} & =(\cos \theta+\sin \theta \tan \phi) \bullet t_{r}, \\
t_{r} & =T_{r}\left(\frac{A_{r}}{A_{s}}\right), \\
\operatorname{RAR} & =\frac{A_{r}}{A_{s}},
\end{aligned}
$$

where $c_{r}$ is the cohesion due to roots $(\mathrm{kPa}), T_{r}$ is the mean tensile strength of roots $(\mathrm{kPa}), \phi$ is the friction angle of the soil (degrees), $\theta$ is the angle of shear distortion (degrees), $A_{r}$ is the area of roots in the plane of the shear surface, $A_{s}$ is the area of the shear surface, and RAR is the root area ratio. The root area ratio and tensile strength are the most important mechanical indicators of the strength of a root system.

However, Pollen and Simon [39] found that models based on equation (1) tended to overestimate root reinforcement. The RipRoot model considers different root system tolerances and the process of gradual root system destruction, and it therefore provides a more reasonable root system and associated enhancement of soil strength. The RipRoot model was therefore selected in this study to estimate the additional cohesion due to roots.

The Bank Stability and Toe Erosion (BSTEM) model proposed by the Agricultural Research Service of the United States is a comprehensive model used to predict the slope foot erosion rate and slope stability. Therefore, the effects of vegetation on slope stability were simulated using the root reinforcement model and the RipRoot model within the BSTEM model. The RipRoot model within the BSTEM model was employed to calculate the root cohesion of vegetation in the study area. When calculating root cohesion, it is usually necessary to determine the species and ages of trees, the relationship between the root diameter and tensile strength, and the distribution of different sized root systems. Tree species of trees were identified by remote sensing, and their ages and root diameters (Table 1) were obtained through a field investigation. According to Burylo et al. [40], the tensile strength of roots, $T_{r}$, decreases with increasing root diameter and follows a simple power-law equation,

$$
T_{r}=\alpha D^{-\beta}
$$

where $T_{r}$ is the tensile strength of roots $(\mathrm{kPa}), \alpha$ and $\beta$ are empirical values depending on the species, and $D$ is the root diameter. The larger the root diameter, the greater the tensile strength.

2.2.5. The Slope Stability Calculation with SINMAP Model under the Combined Impact of Rainfall and Vegetation Roots. Deterministic models based on landslide physics processes are widely used to predict the spatiotemporal stability of shallow
TABLE 1: Values of parameters used in slope stability analysis (SINMAP).

\begin{tabular}{lcccc}
\hline Parameter & $C_{s}\left(k N / \mathrm{m}^{2}\right)$ & $\phi$ & $K(\mathrm{~m} / \mathrm{s})$ & $\rho_{s}\left(\mathrm{~kg} / \mathrm{m}^{3}\right)$ \\
\hline Values & 9.31 & 19.6 & $9 \times 10^{-4}$ & 2700 \\
\hline
\end{tabular}

landslides [41]. To evaluate the spatial distribution of the stability of shallow landslides caused mainly by rainfall, Borga et al. [42] constructed a quantitative evaluation model of shallow landslide stability (Stability Index MaPping, SINMAP) based on the following: a DEM, a coupled steady-state hydrological model, and an infinite slope stability model $[13,20-25]$. SINMAP is a large-scale slope stability model that uses topographic humidity index data obtained from the steady-state hydrological model, slope information obtained from the gridded DEM, maps of the effective catchment area and other GIS maps, and field investigation data. The model can be used to classify and evaluate surface stability [43]. The basic unit of the SINMAP model is a grid cell, which is quick and easy to calculate. However, the square grid in this respect poorly reflects the mechanism of disaster formation. Each slope has a well-defined terrain boundary, and each slope has significantly different characteristics from its adjacent slopes. As the topographic features within slopes are consistent, "the slope" is an idea unit for use in studying landslides. Therefore, in this study, we extended the cell of the original SINMAP model into a slope cell.

We used the SINMAP model to calculate the factor of safety $\left(F_{s}\right)$, which relates to the quotient of the upward and downward sliding forces on a weak structural plane parallel to the ground surface. The formula for calculating $F_{s}$ is as follows [44]:

$$
F_{s}=\frac{c_{r}+c_{s}+\left[\cos ^{2} \theta \rho_{s}\left(D-D_{w}\right)+\left(\rho_{s} g-\rho_{w} g\right) D_{w}\right] \tan \varphi}{D \rho_{s} g \sin \theta \cos \theta+D_{w} \rho_{w} g \sin \theta \cos \theta},
$$

where $c_{r}$ is the cohesion of plant roots $\left(\mathrm{N} / \mathrm{m}^{2}\right), c_{s}$ is the cohesion of soil $\left(\mathrm{N} / \mathrm{m}^{2}\right)$, $\theta$ is the terrain gradient, $\rho_{\mathrm{s}}$ is the moist soil density $\left(\mathrm{kg} / \mathrm{m}^{3}\right), g$ is the gravitational acceleration $(9.81 \mathrm{~N} / \mathrm{kg}), D$ is the soil thickness $(\mathrm{m}), \rho_{\mathrm{w}}$ is the water density $\left(\mathrm{kg} / \mathrm{m}^{3}\right), \varphi$ is the soil friction angle, and $D_{w}$ is the depth of the aquifer from the surface (m).

Its dimensionless expression follows

$$
F_{s}=\frac{C+\cos \theta[1-\omega r] \tan \varphi}{[1+\omega r] \sin \theta},
$$

where is the terrain gradient, $\varphi$ is the soil friction angle, $r$ is the water density divided by the soil density, $C$ is the dimensionless cohesion, and $\omega$ is the topographic wetness index, which was calculated from the TOPMODEL model using the following formula:

$$
\omega=\frac{q a}{T \sin \theta},
$$

where $q$ is the effective rainfall, $a$ is the ratio of the area of rain collection (the catchment area divided by the drainage width), and $T$ is the transmissibility $(T=K Z \cos \theta)$, where 
$K$ is the permeability coefficient and $Z$ is the soil thickness. Surface runoff occurs when the topographic wetness index $(\omega)$ is greater than 1 , and the maximum value of the topographic wetness index $\omega$ is 1 .

$$
\begin{aligned}
\omega & =\min \left(\frac{q a}{T \sin \theta}, 1\right), \\
F_{s} & =\frac{C+\cos \theta[1-\min ((q a / T \sin \theta), 1) r] \tan \varphi}{[1+\omega r] \sin \theta},
\end{aligned}
$$

when $F_{s}>1$, the slope is stable; when $F_{s}=1$, the slope is in a state of limit equilibrium; and when $F_{s}<1$, the slope is unstable. $a$ and $\theta$ were extracted from the DEM, $r$ depends on the density of the soil in the study area, $C$ is the value of cohesion used in this study, and $\varphi$ and $T$ were calculated from the results obtained from laboratory tests and literature surveys. The range of the study area was small, and the internal friction angle, permeability coefficient, and the soil density values were typically identical within it. The values of all parameters are listed in Table 1 .

To study the effect of root cohesion on slope stability, we defined the root coefficient $(R)$ as the influence of root cohesion on stability according to the SINMAP model:

$$
R=\frac{c_{r}}{\left(D \rho_{s} g+D_{\omega} \rho_{w} g\right) \sin \theta \cos \theta}
$$

where $R$ is the root coefficient, $c_{r}$ is the cohesion of plant roots $(\mathrm{kPa}), \theta$ is the terrain gradient, $\rho_{\mathrm{s}}$ is the moist soil density $\left(\mathrm{kg} / \mathrm{m}^{3}\right), g$ is gravitational acceleration $(9.81 \mathrm{~N} / \mathrm{kg})$, and $D$ is soil thickness $(m)$.

\section{Results and Discussion}

3.1. The Field Instigation Result of Root Diameters. We measured the plant diameter and height and the numbers of roots with different root diameters of five dominant plant species in the field. The root depths of the main plant species in the study area were found to range from $30 \mathrm{~cm}$ to $40 \mathrm{~cm}$, and the various vegetative characteristics of the roots are listed in Table 2.

3.2. The Result of Slope Unit Division. The method used to divide slope units was based on a DEM generated from the UAV remote sensing results. In this respect, based on the source cutting method and ridgelines and valley lines, slope units were divided using the GIS platform. The average terrain gradient $(\theta)$ and the ratio of the area of rain collection $(a)$ of each slope unit are shown in Figures 5(a) and 5(b), respectively.

3.3. The Result of Root Cohesion. According to existing research, the relationships between root tensile strength and the root diameters of five dominant plant species in the study area are shown in Table 3.

By considering variations in the mean root tensile strength $\left(T_{r}\right)$ with root diameter, root cohesion for the five vegetation types was calculated using equations (1) and (8) via the RipRoot model, and the results are given in Table 4. The root cohesive forces produced by the five plant species were significantly different and varied from $6.36 \mathrm{kPa}$ (Yushania basihirsuta) to $17.6 \mathrm{kPa}$ (Fagus longipetiolata). Such variations relate to differences between the root area ratios and tensile strengths.

\subsection{Slope Stability under Different Rainfall Conditions and} When considering and Not considering Root Cohesion. Based on the characteristics of the study area and daily rainfall data for the past 50 years, it was assumed that the effective rainfall amounts were $50 \mathrm{~mm}, 105.3 \mathrm{~mm}$, and $207.6 \mathrm{~mm}$. The SINMAP model was used to calculate the stability factor for each slope under these three rainfall amounts. Steady-state classification was then conducted according to the stability coefficient. The slope stability coefficient obtained using equation (9) is an absolute value, and it directly reflects the degree of slope stability. It is of note that the classification of safety level standards for slope stability factors is currently not uniform. Rainfall erosion in the study area is extremely strong and it results in large slope disturbances. According to the geological environment and the degree of human activity in the study area, the safety standard for slope stability was integrated.

According to the calculated $F_{s}$ value, slope stability was divided into five grades: unstable $\left(F_{s}<1.00\right)$, potentially unstable $\left(F_{s}\right.$ is $\left.1.00-1.25\right)$, basically stable $\left(F_{s}\right.$ is $\left.>1.25-1.50\right)$, increasingly stable $\left(F_{s}\right.$ is $\left.>1.50-1.75\right)$, and stable $\left(F_{s}>1.75\right)$, and the results are shown in Figures 6-8 with respect to different amounts of precipitation. With an increase in the amount of effective rainfall, the proportion of unstable regions that are $F_{s}<1.00$ gradually increases.

When root cohesion was not considered, the proportion of such slope units increased from $1.08 \%$ under $50 \mathrm{~mm}$ of precipitation to $11.7 \%$ at $207 \mathrm{~mm}$, and when root cohesion was considered, the proportion of slope units increased from $11.5 \%$ under $50 \mathrm{~mm}$ of rainfall to $34.36 \%$ under $207 \mathrm{~mm}$. According to the distribution of past disaster sites, there has been a significant increase in the proportion of landslide disaster points distributed in unstable regions in relation to the effective rainfall amounts. It is thus evident that landslides in this area have been significantly affected by rainfall.

In this study, the receiver operating characteristic (ROC) analysis method was used to analyze and evaluate the model results under the three rainfall conditions, both in consideration of roots and without the consideration of roots. The sensitivity index (where a landslide area is identified as an unstable slope) was used as the ordinate, and a specificity of 1- (determining an area as stable, unstable, and misjudgments) was used as the abscissa. The size of the area under the curve (AUC) was used to measure the accuracy of the model's calculations. In this respect, a larger area indicates a stronger ability to predict and evaluate, and a curve closer to the upper-left corner indicates a higher model accuracy. When considering and not considering the root system effect, $F_{s}<1$ was determined as unstable and assigned a value of 1 , and $F_{s}>1$ was determined as stable and assigned a value of 0 . Additionally, a slope for which a landslide had occurred was assigned a value of 1 , and a unit in which a landslide had not occurred was assigned a value of 0 . 
TABLE 2: Root diameters of five dominant plant species identified in the study area.

\begin{tabular}{lcccccccc}
\hline Root diameter & $0-1$ & $1-2$ & $2-3$ & $3-5$ & $5-10$ & $10-20$ & $20-40$ & Sampling point \\
\hline Cunninghamia lanceolata & 0 & 47 & 16 & 17 & 18 & 8 & 10 & 8 \\
Pinus massoniana & 0 & 0 & 44 & 39 & 54 & 28 & 17 & 17 \\
Pinus kwangtungensis & 0 & 0 & 47 & 42 & 28 & 19 & 27 & 9 \\
Fagus longipetiolata & 0 & 10 & 58 & 49 & 62 & 42 & 0 \\
Yushania basihirsuta & 25 & 15 & 24 & 20 & 5 & 0 & 0 & 8 \\
\hline
\end{tabular}

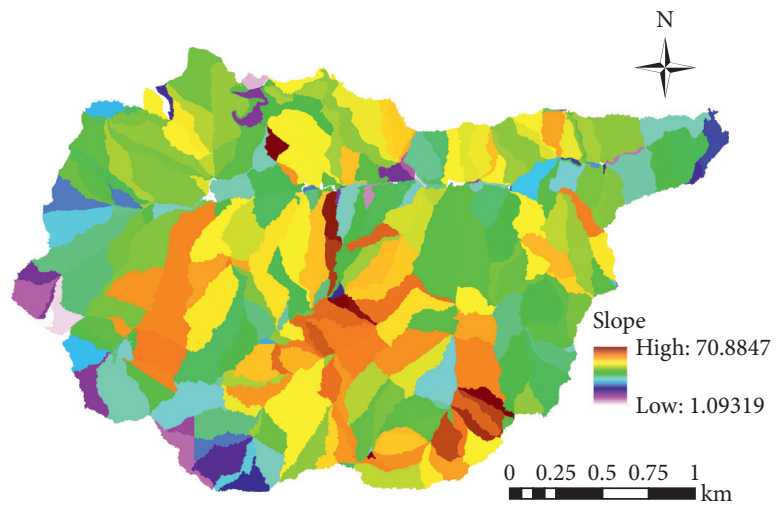

(a)

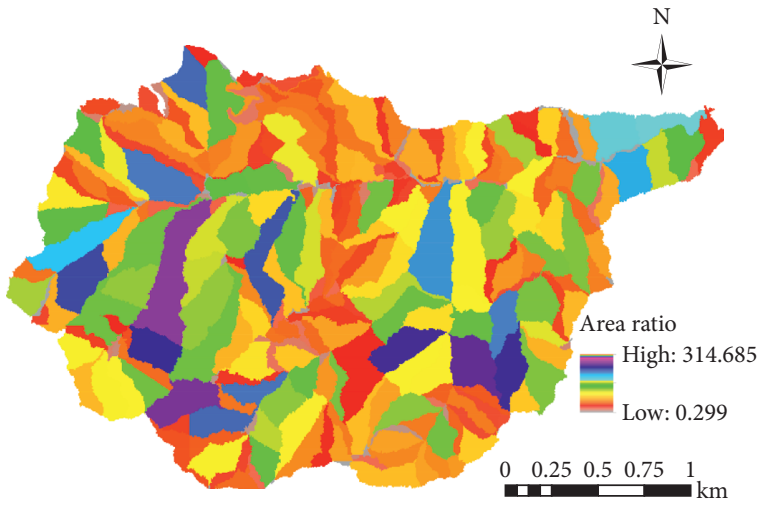

(b)

FIGURE 5: The result of slope unit division in the study area: (a) the average terrain gradient $(\theta)$ of each slope unit and (b) the area ratio of rain collection (a) of slope unit.

TABLE 3: Relationship between tensile strength and the root diameter of main plant species in the study area.

\begin{tabular}{lc}
\hline Species & Relationship \\
\hline Cunninghamia lanceolata & $T_{r}=12.349 D^{-0.262}$ \\
Pinus massoniana & $T_{r}=3.503 D^{-0.4171}$ \\
Pinus kwangtungensis & $T_{r}=41.99 D^{-0.11}$ \\
Fagus longipetiolata & $T_{r}=70.61 D^{-0.847}$ \\
Yushania basihirsuta & $T_{r}=22.6829 D^{-0.221}$ \\
\hline
\end{tabular}

TABLE 4: Area under the curve obtained using the SINMAP model under different precipitation amounts.

\begin{tabular}{lccc}
\hline Precipitation & $50 \mathrm{~mm}$ & $105.3 \mathrm{~mm}$ & $207.6 \mathrm{~mm}$ \\
\hline Without contribution of roots & 0.624 & 0.915 & 0.9 \\
With contribution of roots & 0.651 & 0.962 & 0.956 \\
\hline
\end{tabular}

The results of disaster conditions and the safety factors associated with the three rainfall conditions were imported into the SPSS software to conduct the ROC analysis, and the results are shown in Figure 9. As shown in the figure, introducing root cohesion into the model improved the prediction accuracy of the model, which was highest when the rainfall was 103.5. The AUC surface area when considering the contribution of roots was 0.962 , and that without considering the contribution of roots was 0.915 .

3.5. Effect of Root Cohesion on the Safety Factor. The influence of root cohesion on the factor of safety $\left(F_{S}\right)$ of an infinite slope considering the three precipitation levels is shown in Figure 10. It is evident that root cohesion increases slope stability. However, the safety factor does not change linearly with the change in root cohesion, but it rather shows a gradual changing trend. It can be inferred from formula (10) that, under the same surface soil and hydrological environment, the coefficient of the action of the root system is mainly affected by the slope of the terrain. In addition, when the cohesive force of the root system increases to a certain threshold, the rate of increase in the safety factor begins to slow. In the interval of $0-45^{\circ}$, the coefficient of action of the root system is positively correlated with the slope; that is, the larger the slope with the same vegetation type, the more effective the effect on slope stability. The root system had the largest coefficient of action with a slope of $45^{\circ}$, but when the slope was in the range of $45-90^{\circ}$, the root coefficient of action had a negative correlation with slope; that is, the greater the slope with the same kind of vegetation, the weaker the stability of the slope.

The root system coefficient $(R)$ was found to be affected by the slope and the soil thickness. Under the same soil type and soil thickness, the influence of vegetation on slope stability was controlled mainly by the degree of slope. The safety factor $(F s)$ did not change linearly with changes in root cohesion. When the cohesive force of the root system increased to a certain threshold, the rate of increase in the safety factor began to slow.

3.6. Discussion. The forest coverage rate in South China exceeds $90 \%$, and plant roots play a very important role in the stability of landslides. At present, most studies on the stability of high-coverage vegetation landslides in South China do not consider the role of roots on the stability of landslides, nor do 


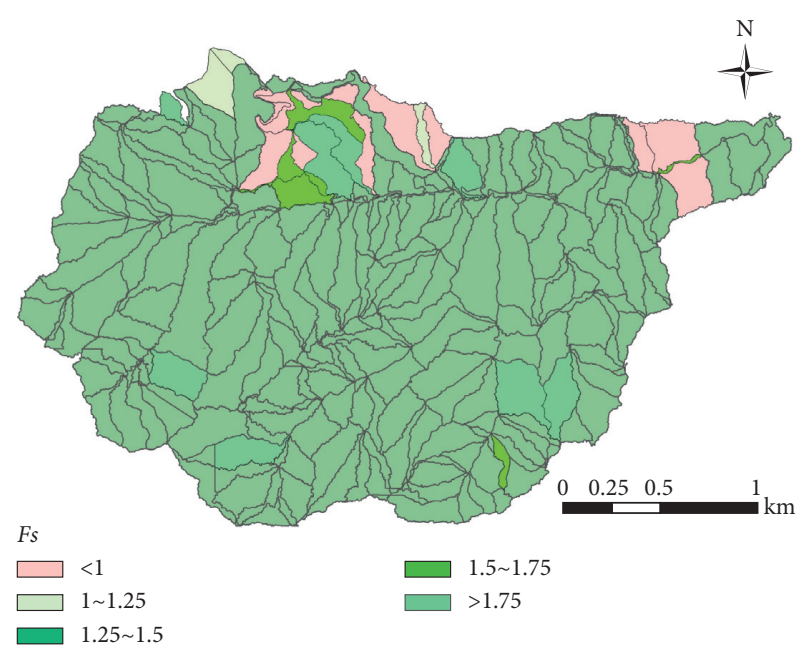

(a)

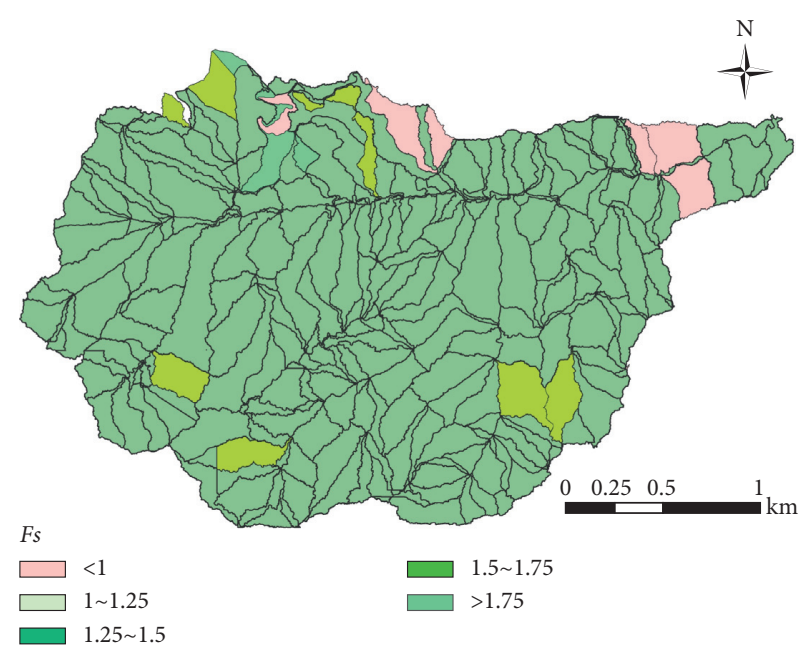

(b)

FIGURE 6: Slope stability under $50 \mathrm{~mm}$ rainfall conditions (a) without and (b) with the contribution of roots.


(a)

FiguRE 7: Slope stability under $105.3 \mathrm{~mm}$ rainfall conditions (a) without and (b) with the contribution of roots.

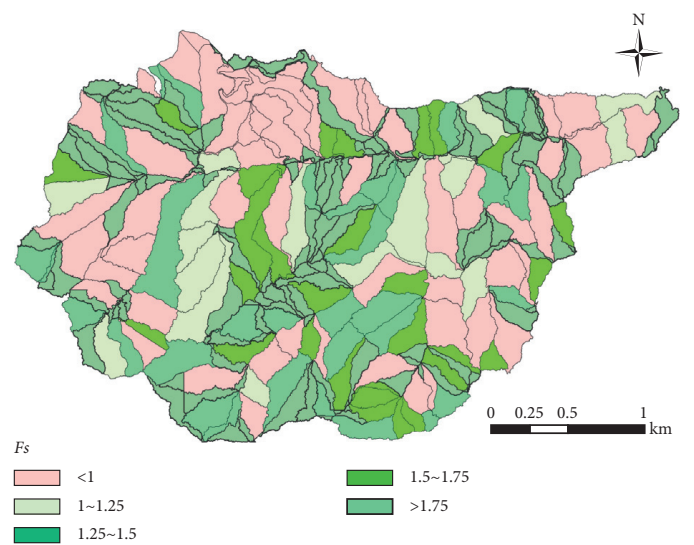

(a)

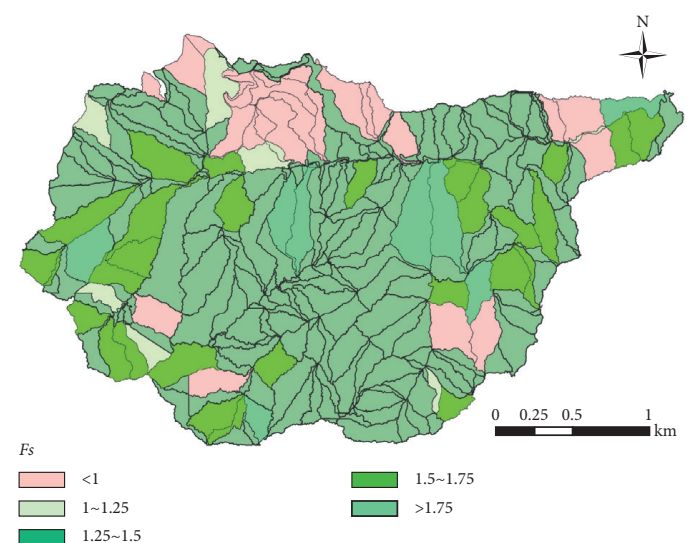

(b)

FIGURE 8: Slope stability under $207.6 \mathrm{~mm}$ rainfall conditions (a) without and (b) with the contribution of roots. 


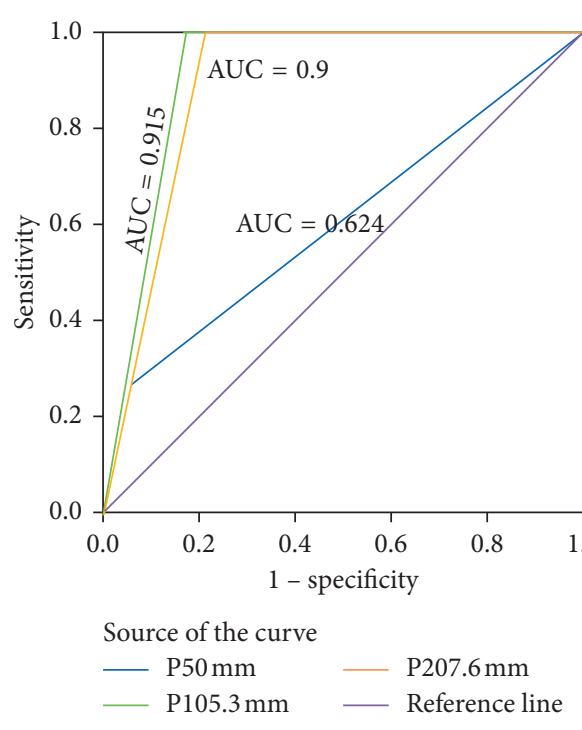

(a)



(b)

FIGURE 9: ROC curves of the SINMAP model under different precipitation levels (a) without and (b) with the contribution of roots.

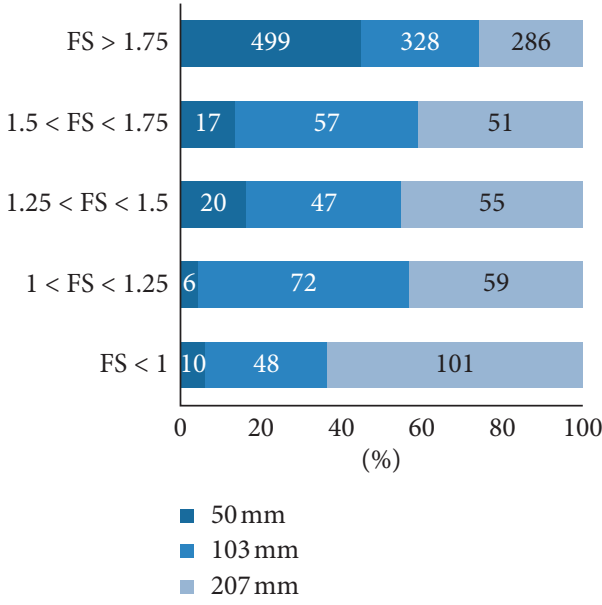

(a)

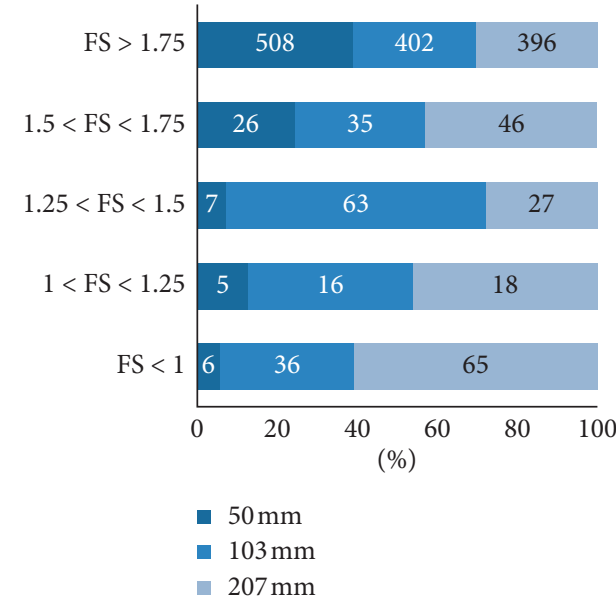

(b)

Figure 10: Percentage occurrence of different-grade shallow landslides under different precipitation levels (a) without and (b) with the contribution of roots.

they introduce the root-soil composite cohesion into the analysis of landslide stability, which seriously affects the calculation accuracy of landslide stability in areas with high vegetation coverage in South China. This study explored the influence of the additional tensile stress and cohesion of the root system on the strength of the soil, so as to analyze the influence of the root system on the factor of landslide safety (Fs). We modified the SINMAP model, extended its grid unit to slope unit, calculated the slope stability coefficient of each slope unit in the study area with and without roots, and used the landslide inventory data and the ROC curve to validate the study results. The results show that, considering the root-soil composite cohesion, the calculation accuracy of landslide stability can be improved to a large extent.
The mechanical properties of the root-soil complex mainly include shear strength, elastic modulus, ultimate tensile strength of roots, etc. There are many influencing factors, which can be roughly divided into two categories: (1) soil factors, such as soil water content, cohesion, internal friction angle; and (2) plant factors, such as tree age, root diameter, root length density, total root length, root area ratio, and root diameter class. Different scholars chose different plants, so the generalization of their research results to other plants has yet to be found in commonality. In addition, the study area is different, and the geological conditions and the nature of the soil are also different, which is also a problem that needs to be paid attention to in future research. 
The model in this paper is mainly aimed at the main factors affecting the stability of the landslide in South China, mainly considering the root diameter of the vegetation, the strength of the soil, the thickness of the soil, the permeability coefficient of the soil, the effective rainfall, and other factors. The parameters were simplified in the model operation process, and slight differences in the study area were neglected to some extent, which would have had some influence on the accuracy of the evaluation results. In a future study, the water and soil parameters will be assigned through experimental methods, and the intrinsic relationship between vegetation and slope stability under different rainfall conditions will be further elucidated.

\section{Conclusions}

The objective of this study was to propose an improved physically based SINMAP model for predicting rainfallinduced landslides in densely vegetated areas, with the aim of providing a support for disaster mitigation in mountainous areas. The unit of the SIMMAP model was improved using a slope unit that can reflect landslide disasters, facilitate the rapid calculation of results, and provide calculation results that are comparatively more realistic. Several conclusions can be made, and these are presented as follows.

(1) The root cohesion force was found to differ considerably between the main plant species in the study area. Root cohesion is mainly related to root diameter; as the root diameter increases, the root crosssectional area also rapidly increases, with the proportion of lignification of the root system; therefore, the maximum tensile strength of the roots rapidly increases. However, the same plant species has a different effect on slope stability under different geological conditions.

(2) Under three different rainfall conditions, the stability characteristics of each slope unit were calculated using the improved SINMAP model while considering vegetation root cohesion; the results spatially reflected the slope stability under different conditions. The calculation results also showed that the accuracy of the improved SINMAP model improved when root cohesion was considered. In addition, as the amount of rainfall increased, there was an increase in the area where potentially dangerous landslides could occur.

(3) The Nanling Mountains are characterized by high vegetation coverage, and the roots of plants form a continuous root net in the shallow soil beneath the forest, forming a special composite material. The soil has a relatively low-strength soil (matrix), but the root system (fiber) has a high tensile strength and is embedded within the soil matrix; this is important for controlling shallow landslides. The root cohesion derived from the root-soil interaction model in this study is only an approximate value of the actual amount, but it reveals the potential of using vegetation to protect slopes. This study thus provides a theoretical basis for planting vegetation to prevent disasters by protecting slopes.

\section{Data Availability}

The data used to support the findings of this study are available from the corresponding author upon request.

\section{Conflicts of Interest}

The authors declare that there are no conflicts of interest regarding the publication of this paper.

\section{Acknowledgments}

The authors thank Shaoxiong Yuan and Jun Chen for their efforts and help in field investigation, UAV aerial photography, and data curation. The authors also would like to thank Editage (http://www.editage.cn) for English language editing. This research was supported by the National Natural Science Foundation of China (41771024 and 41977413), Key Special Project for Introduced Talents Team of Southern Marine Science and Engineering Guangdong Laboratory (Guangzhou), China (GML2019ZD0301), GDAS’ Project of Science and Technology Development (2020GDASYL20200301003, 2020GDASYL-040101, and 2020GDASYL20200102002), and Guangdong Provincial Science and Technology Program (2018B030324002 and 2018B030324001).

\section{References}

[1] C. Gallage, T. Abeykoon, and T. Uchimura, "Instrumented model slopes to investigate the effects of slope inclination on rainfall-induced landslides," Soils and Foundations, vol. 61, no. 1, pp. 160-174, 2021.

[2] E. E. Chikalamo, O. C. Mavrouli, J. Ettema, C. J. V. Westen, and A. Mustofa, "Satellite-derived rainfall thresholds for landslide early warning in Bogowonto Catchment, Central Java, Indonesia," International Journal of Applied Earth $\mathrm{Ob}$ servation and Geoinformation, vol. 89, Article ID 102093, 2020.

[3] S. Segoni, L. Piciullo, and S. L. Gariano, "A review of the recent literature on rainfall thresholds for landslide occurrence," Landslides, vol. 15, no. 8, pp. 1483-1501, 2018.

[4] T. Abeykoon, C. Gallage, B. Dareeju, and J. Trofimovs, "Realtime monitoring and wireless data transmission to predict rain-induced landslides in critical slopes," Australian Geomechanics Journal, vol. 53, no. 3, pp. 61-76, 2018.

[5] Q. H. Gong and G. Q. Huang, "On the application of the slope element unit method to the shallow landslide risk-prevention mapping with a case study sample of Songgang watershed," Journal of Safety and Environment, vol. 17, no. 2, pp. 615-620, 2017.

[6] K. Hawas, S. Muhammad, and A. Muhammad, "Landslide susceptibility assessment using Frequency Ratio, a case study of northern Pakistan," The Egyptian Journal of Remote Sensing and Space Science, vol. 22, no. 1, pp. 11-24, 2019.

[7] A. Bhardwaj, R. J. Wasson, A. D. Ziegler, W. T. L. Chow, and Y. P. Sundriyal, "Characteristics of rain-induced landslides in the Indian Himalaya: a case study of the Mandakini 
Catchment during the 2013 flood," Geomorphology, vol. 330, pp. 100-115, 2019.

[8] M. Juliev, M. Mergili, I. Mondal, B. Nurtaev, A. Pulatov, and J. Hübl, "Comparative analysis of statistical methods for landslide susceptibility mapping in the Bostanlik District, Uzbekistan," The Science of the Total Environment, vol. 653, pp. 801-814, 2019.

[9] J. Gao, Z. Zahng, and C. Z. Wang, "Susceptibility assessment of landslides triggered by earthquakes in the Western Sichuan Plateau," Catena, vol. 175, pp. 63-76, 2019.

[10] W. Y. Florence, K. Frankie, and L. C. Lo, "From landslide susceptibility to landslide frequency: a territory-wide study in Hong Kong," Engineering Geology, vol. 242, pp. 12-22, 2018.

[11] T. König, H. J. H. Kux, and R. M. Mendes, "Shalstab mathematical model and WorldView-2 satellite images to identification of landslide-susceptible areas," Natural Hazards, vol. 97, no. 3, pp. 1127-1149, 2019.

[12] S. K. Min, "Influence of subsurface flow by Lidar DEMs and physical soil strength," Catena, vol. 182, Article ID 104137, 2019.

[13] E. Bueechi, J. Klimeš, H. Frey, C. Huggel, T. Strozzi, and A. Cochachin, "Regional-scale landslide susceptibility modelling in the Cordillera Blanca, Peru-a comparison of different approaches," Landslides, vol. 16, no. 2, pp. 395-407, 2019.

[14] F. Keles and H. A. Nefeslioglu, "Infinite slope stability model and steady-state hydrology-based shallow landslide susceptibility evaluations: the Guneysu catchment area (Rize, Turkey)," Catena, vol. 200, Article ID 105161, 2021.

[15] M. Alvioli and R. L. Baum, "Parallelization of the TRIGRS model for rainfall-induced landslides using the message passing interface," Environmental Modelling \& Software, vol. 81, pp. 122-135, 2016.

[16] A. Dikshit, N. Satyam, and B. Pradhan, "Estimation of rainfall-induced landslides using the TRIGRS model," Earth Systems and Environment, vol. 3, no. 3, pp. 575-584, 2019.

[17] Y.-l. Chen, D.-h. Chen, Z.-c. Li, and J.-b. Huang, "Preliminary studies on the dynamic prediction method of rainfalltriggered landslide," Journal of Mountain Science, vol. 13, no. 10, pp. 1735-1745, 2016.

[18] N. Saadatkhah, A. Kassim, L. M. Lee, and K. Hulu, "Hulu Kelang, Malaysia regional mapping of rainfall-induced landslides using TRIGRS model," Arabian Journal of Geosciences, vol. 8, no. 5, pp. 3183-3194, 2015.

[19] L. Weidner, T. Oommen, R. Escobar-Wolf, K. S. Sajinkumar, and R. A. Samuel, "Regional-scale back-analysis using TRIGRS: an approach to advance landslide hazard modeling and prediction in sparse data regions," Landslides, vol. 15, no. 12, pp. 2343-2356, 2018.

[20] G. P. Michel, M. Kobiyama, and R. F. Goerl, "Comparative analysis of SHALSTAB and SINMAP for landslide susceptibility mapping in the Cunha River basin, southern Brazil," Journal of Soils and Sediments, vol. 14, no. 7, pp. 1266-1277, 2014.

[21] G. L. Paulín and M. Bursik, "Assessing a physical-based approach for landslide susceptibility in the Río La Carbonera, SE flank of Pico de Orizaba volcano, Mexico," Zeitschrift für Geomorphologie, vol. 61, no. 3, pp. 181-189, 2017.

[22] M. Lazzari and M. Piccarreta, "Landslide disasters triggered by extreme rainfall events: the case of montescaglioso (Basilicata, Southern Italy)," Geoscience, vol. 8, no. 10, 377 pages, 2018.

[23] J. Dou, A. P. Yunus, D. Tien Bui et al., "Assessment of advanced random forest and decision tree algorithms for modeling rainfall-induced landslide susceptibility in the Izu-
Oshima Volcanic Island, Japan," The Science of the Total Environment, vol. 662, pp. 332-346, 2019.

[24] G. Domènech, M. Alvioli, and J. Corominas, "Preparing firsttime slope failures hazard maps: from pixel-based to slope unit-based," Landslides, vol. 17, no. 2, pp. 249-265, 2020.

[25] W. Lin, K. Yin, N. Wang, Y. Xu, Z. Guo, and Y. Li, "Landslide hazard assessment of rainfall-induced landslide based on the CF-SINMAP model: a case study from Wuling mountain in Hunan province, China," Natural Hazards, vol. 106, no. 1, pp. 679-700, 2021.

[26] M. Bordoni, C. Meisina, A. Vercesi et al., "Quantifying the contribution of grapevine roots to soil mechanical reinforcement in an area susceptible to shallow landslides," Soil and Tillage Research, vol. 163, pp. 195-206, 2016.

[27] L. J. Su, B. L. Hu, Q. J. Xie, F. W. Yu, and C. L. Zhang, "Experimental and theoretical study of mechanical properties of root-soil interface for slope protection," Journal of Mountain Science, vol. 17, no. 11, pp. 197-208, 2020.

[28] D.-b. Zhang, Y. Zhang, and T. Cheng, "Measurement of grass root reinforcement for copper slag mixed soil using improved shear test apparatus and calculating formulas," Measurement, vol. 118, pp. 14-22, 2018.

[29] S. Bordoloi, V. Kashyap, A. Garg, S. Sreedeep, L. Wei, and S. Andriyas, "Measurement of mechanical characteristics of fiber from a novel invasive weed: a comprehensive comparison with fibers from agricultural crops," Measurement, vol. 113, pp. 62-70, 2018.

[30] A. Cislaghi, M. Bordoni, C. Meisina, and G. B. Bischetti, "Soil reinforcement provided by the root system of grapevines: quantification and spatial variability," Ecological Engineering, vol. 109, pp. 169-185, 2017.

[31] C. Ye, Z. Guo, Z. Li, and C. Cai, "The effect of Bahiagrass roots on soil erosion resistance of Aquults in subtropical China," Geomorphology, vol. 285, pp. 82-93, 2017.

[32] C. Vergani, F. Giadrossich, P. Buckley et al., "Root reinforcement dynamics of European coppice woodlands and their effect on shallow landslides: a review," Earth-Science Reviews, vol. 167, pp. 88-102, 2017.

[33] A. Gonzalez-Ollauri and S. B. Mickovski, "Plant-soil reinforcement response under different soil hydrological regimes," Geoderma, vol. 285, pp. 141-150, 2017.

[34] E. Dazio, M. Conedera, and M. Schwarz, "Impact of different chestnut coppice managements on root reinforcement and shallow landslide susceptibility," Forest Ecology and Management, vol. 417, pp. 63-76, 2018.

[35] A. P. Dong, J. Chen, F. G. Wang, and F. W. Xing, "Study on vegetation of nanling national nature Reserve in Guangdong province," Journal of Zhongkai University of Agriculture and Engineering, vol. 25, no. 2, pp. 1-7, 2012, in Chinese.

[36] L. J. Waldron, "The shear resistance of root-permeated homogeneous and stratified soil," Soil Science Society of America Journal, vol. 41, no. 5, pp. 843-849, 1977.

[37] T. H. Wu, W. P. McKinnell III, and D. N. Swanston, "Strength of tree roots and landslides on pwi," Canadian Geotechnical Journal, vol. 16, no. 1, pp. 19-33, 1979.

[38] L. J. Waldeon and S. Dakessian, "Soil reinforcement by roots: calculation of increased soil shear resistance from root properties," Soil Science, vol. 132, pp. 427-435, 1981.

[39] N. Pollen and A. Simon, "Estimating the mechanical effects of riparian vegetation on stream bank stability using a fiber bundle model," Water Resources Research, vol. 41, pp. 70-25, 2005.

[40] M. Burylo, C. Hudek, and F. Rey, "Soil reinforcement by the roots of six dominant species on eroded mountainous marly 
slopes (Southern Alps, France)," Catena, vol. 84, no. 1-2, pp. 70-78, 2010.

[41] J. C. Xu, Y. Q. Shang, K. F. Chen, and J. F. Yang, "Analysis of shallow landslide stability under intensive rainfall," Chinese Journal of Rock Mechanics and Engineering, vol. 24, no. 18, pp. 3246-3251, 2005.

[42] M. Borga, G. D. Fontana, D. D. Ros, and L. Marchi, "Shallow landslide hazard assessment using a physically based model and digital elevation data," Environmental Geology, vol. 35, no. 2-3, pp. 81-88, 1998.

[43] L. Wu, W. C. Zhang, D. Zhang, and Z. Jie, "Remote sensing \& GIS-Based distributed hillslope stability: quantitative evaluation model," Chinese Geographical Science, vol. 24, no. 4, pp. 458-464, 2004.

[44] H. X. Lan, F. Q. Wu, and C. H. Zhou, "Predict the crisis of rainfall-induced landslides based on GIS," Chinese Science Bulletin, vol. 48, no. 5, pp. 507-512, 2003, in Chinese. 